DOI: http://dx.doi.org/10.20435/1399

\title{
Responsabilidade civil por dano ambiental decorrente do rompimento das barragens do Fundão, em Mariana, Minas Gerais
}

\begin{abstract}
Civil liability for environmental damage caused by the disruption of the Fundão dams in Mariana, Minas Gerais
\end{abstract}

Hilton Neves Filho ${ }^{1}$ Daiane Machado Rezende ${ }^{2}$ Maria Luiza Santos Costa $^{3}$ Roy Reis Friede ${ }^{4}$

${ }^{1}$ Mestrando no Programa de Mestrado Profissional em Desenvolvimento Local, Centro Universitário Augusto Motta (UNISUAM). Coordenador do NPJ, Universidade Iguaçu (UNIG).

E-mail: guardiaodalux@gmail.com

${ }^{2}$ Mestranda em Desenvolvimento Local, Universidade Augusto Motta (UNISUAM). Professora, advogada orientadora e coordenadora do Escritório de Assistência Jurídica (ESAJUR), vinculado ao Centro de Formação Profissional, da Faculdade de Ciências Jurídicas e Sociais Aplicadas (UNIG).E-mail: daianemr@outlook.com

${ }^{3}$ Mestrando em Desenvolvimento Local, Centro Universitário Augusto Motta. Professora e advogada orientadora da Universidade Iguaçu (UNIG).E-mail: luiza4735@gmail.com

${ }^{4}$ Doutor em Direito Político, UFRJ; Mestre em Direito Político e Direito. Professor permanente do Programa de Mestrado em Desenvolvimento Local (MDL) do Centro Universitário Augusto Motta (UNISUAM), professor conferencista da Escola da Magistratura do Estado do Rio de Janeiro, professor emérito da Escola de Comando e Estado Maior do Exército e desembargador federal - Tribunal Regional Federal da $2^{\underline{a}}$ Região. E-mail: reisfriede@hotmail.com 


\section{RESUMO}

O desastre ambiental em Mariana, Minas Gerais, decorrente do rompimento das barragens de rejeitos da Mineradora Samarco, é uma catástrofe sem precedentes face à magnitude de seus efeitos devastadores, quer sejam eles incidentes sobre o conjunto de bens da sociedade civil vitimada, quer sobre o bioma. 0 fato atrai a responsabilização por dano de todos que, de alguma forma, colaboraram para o evento, sendo necessário demonstrar os agentes, o nexo de causalidade e a legislação aplicável ao caso. Assim, pretende o presente artigo colocar em evidência a responsabilidade civil da mineradora e dos entes estatais envolvidos, cujas condutas, comissivas ou omissivas, contribuíram de alguma forma para o evento que, em 5 de novembro de 2015, culminou no desastre, destruindo por completo o distrito de Bento Rodrigues e impactando, de forma negativa, as populações ribeirinhas, a fauna e a flora do Rio

Doce, desde a área de sua eclosão até o Oceano Atlântico.

PALAVRAS-CHAVE

catástrofe ambiental Samarco responsabilidade civil

\section{ABSTRACT}

The environmental disaster in Mariana, Minas Gerais, caused by the disruption of the mining company Samarco tailings dams, is an unprecedented catastrophe in what regards the magnitude of its devastating effects, whether considering the goods of the victimized people or the biome. The fact attracts the civil liability to every subject that somehow contributed to the event, being necessary to evidence the agents, causation and the law applicable to the case. Therefore, the present article intends to analyze the liability of the mining company and the State entities involved, whose conduct, commissive or omissive, contributed in some way to the event occurred on November $5^{\text {th }}, 2015$, which culminated in the disaster, destroying completely the district of Bento Rodrigues and impacting negatively the Rio Doce coastal communities, fauna and flora, from the disruption area until the Atlantic Ocean.

KEY WORDS

environmental disaster

Samarco

civil liability 
Responsabilidade civil por dano ambiental decorrente do rompimento das barragens do Fundão, em Mariana, Minas Gerais

\section{INTRODUÇÃO}

Em 5 de novembro de 2015, uma após a outra, ocorreu a quebra de duas barragens de resíduos da mineradora Samarco S/A, localizada em Mariana, Minas Gerais, arrasando, entre outros, o distrito de Bento Rodrigues, culminando por disseminar milhares de metros cúbicos de detritos de mineração no vale do Rio Doce.

A torrente de detritos composta principalmente de rejeitos de minério de ferro e outros produtos tóxicos que contaminaram todo o sistema hídrico rio abaixo, bem como a própria calha do rio Doce, causou um desastre ambiental de proporções gigantescas, talvez a maior já acontecida entre nós.

0 desastre, entre outras fatalidades, acarretou o óbito de várias pessoas da comunidade local, varreu do mapa o povoado de Bento Rodrigues, desestruturou o frágil equilíbrio ambiental, provocando a devastação das estruturas naturais, sejam elas vegetais, aquáticas ou animais. Após o desastre, a pesca de subsistência das populações ribeirinhas ficou impraticável, e a distribuição de água potável aos habitantes das cidades que se serviam da água do Rio Doce cessou. Houve também a perda de estruturas públicas relativas aos municípios que do rio dependiam para fornecimento da agua à população.

Muitas condições foram levantadas como possíveis causas justificadoras da hedionda calamidade, inclusive abalo sísmico, porém por mais que surjam argumentos em socorro dos entes que deveriam assegurar a estabilidade daquelas estruturas, nada poderá ter o condão de desonerar os responsáveis, haja vista que todas as possibilidades precisariam estar consideradas para sua construção, inclusive tremor de terra, uma vez que não se pode admitir falha nos protocolos em edificações daquele porte.

A dimensão do problema e seu impacto, sobre a sociedade e o meio ambiente, atraem as disciplinas contidas em diversos 
Hilton NEVES FILHO; Daiane Machado REZENDE; Maria Luiza Santos COSTA;

Roy Reis FRIEDE

diplomas, contudo, no presente artigo, buscar-se-á somente evidenciar a questão da responsabilidade civil por dano ambiental.

\section{DA DISCIPLINA SOBRE BARRAGENS, DO PROBLEMA E SUA ECLOSÃO}

Face a riscos potenciais, o Legislador estabeleceu a Lei 12.334/2010, tratando da Política Nacional de Segurança de Barragens destinadas à acumulação de água para quaisquer usos, à disposição final ou temporária de rejeitos e a acumulação de resíduos industriais. A Lei em comento, em seu Capítulo Segundo, traça as seguintes regras:

Art. $3^{0}$ São objetivos da Política Nacional de Segurança de Barragens (PNSB):

I - garantir a observância de padrões de segurança de barragens de maneira a reduzir a possibilidade de acidente e suas consequências;

II - regulamentar as ações de segurança a serem adotadas nas fases de planejamento, projeto, construção, primeiro enchimento e primeiro vertimento, operação, desativação e de usos futuros de barragens em todo o território nacional;

III - promover o monitoramento e o acompanhamento das ações de segurança empregadas pelos responsáveis por barragens;

O Capítulo Terceiro aduz sobre fundamentos e fiscalização, estabelecendo:

Art. $4^{0}$ São fundamentos da Política Nacional de Segurança de Barragens (PNSB):

I - a segurança de uma barragem deve ser considerada nas suas fases de planejamento, projeto, construção, primeiro enchimento e primeiro vertimento, operação, desativação e de usos futuros;

II - a população deve ser informada e estimulada a participar, direta ou indiretamente, das ações preventivas e emergenciais;

III - o empreendedor é o responsável legal pela segurança da barragem, cabendo-lhe o desenvolvimento de ações para garanti-la; 
IV - a promoção de mecanismos de participação e controle social;

$\mathrm{V}$ - a segurança de uma barragem influi diretamente na sua sustentabilidade e no alcance de seus potenciais efeitos sociais e ambientais.

Art. $5^{\circ}$ A fiscalização da segurança de barragens caberá, sem prejuízo das ações fiscalizatórias dos órgãos ambientais integrantes do Sistema Nacional do Meio Ambiente (Sisnama):

I - à entidade que outorgou o direito de uso dos recursos hídricos, observado o domínio do corpo hídrico, quando o objeto for de acumulação de água, exceto para fins de aproveitamento hidrelétrico;

II - à entidade que concedeu ou autorizou o uso do potencial hidráulico, quando se tratar de uso preponderante para fins de geração hidrelétrica;

III - à entidade outorgante de direitos minerários para fins de disposição final ou temporária de rejeitos;

IV - à entidade que forneceu a licença ambiental de instalação e operação para fins de disposição de resíduos industriais.

Dessa forma, constata-se que, além dos órgãos componentes do Sistema Nacional do Meio Ambiente, a diversas outras entidades também incumbiria a fiscalização da segurança daquelas barragens, nesse sentido; ressalte-se, ainda, o disposto no inciso II, do artigo 4ํㅡㄹ da Lei 12.334/2010, que afirma que até mesmo a população deveria ser informada e estimulada a participar, direta ou indiretamente, das ações preventivas e emergenciais.

De acordo com a Lei no 6.938/81, que instituiu a Política Nacional de Meio Ambiente, o SISNAMA é composto de:

Conselho de Governo: Órgão superior do sistema que reúne todos os ministérios e a Casa Civil da Presidência da República na função de formular a política nacional de desenvolvimento do País, levando em conta as diretrizes para o meio ambiente.

Conselho Nacional do Meio Ambiente (CONAMA): órgão consultivo e deliberativo, formado por representantes dos diferentes setores do governo (em âmbitos federal, estadual e 
municipal), do setor produtivo e da sociedade civil. Assessora o Conselho de Governo e tem a função de deliberar sobre normas e padrões ambientais.

Ministério do Meio Ambiente (MMA): órgão central, com a função de planejar, supervisionar e controlar as ações referentes ao meio ambiente em âmbito nacional.

Instituto Brasileiro de Meio Ambiente e dos Recursos Naturais Renováveis (IBAMA): encarrega-se de executar e fazer executar as políticas e as diretrizes nacionais para o meio ambiente. É o órgão executor.

Órgãos Seccionais: entidades estaduais responsáveis pela execução ambiental nos estados, ou seja, as secretarias estaduais de meio ambiente, os institutos criados para defesa ambiental.

Órgãos locais ou entidades municipais: responsáveis pelo controle e fiscalização ambiental nos municípios.

0 modelo de gestão definido pela Política Nacional de Meio Ambiente baseia-se no princípio do compartilhamento e da descentralização das responsabilidades pela proteção ambiental entre os entes federados e com os diversos setores da sociedade.

Como se depreende, no que toca à segurança das barragens, muitos órgãos deveriam participar do monitoramento e fiscalização, sejam eles federais, estaduais e municipais, além, é claro, da própria mineradora. Logo o fato calamitoso aponta para uma falha sistêmica, em que muitos, por certo, contribuíram de alguma forma para a eclosão do evento, sendo todos, portanto, corresponsáveis.

O Brasil possui 14.966 barragens cadastradas nacionalmente, junto à Agência Nacional de Águas, que, pela esfera federal, também é órgão fiscalizador. Tal agência divulgou em seu último relatório, datado de 2014, que, do total de barragens existentes em seu cadastro, 432 foram fiscalizadas, o que aponta para o índice de apenas 2,89\% (BRASIL, 2014).

A legislação antes citada, Lei 12.334/2010, estabelece critérios para avaliação de riscos em segurança de barragens em 
Responsabilidade civil por dano ambiental decorrente do rompimento das barragens do Fundão, em Mariana, Minas Gerais

função das características técnicas, do estado de conservação do empreendimento e do atendimento ao Plano de Segurança estabelecido para o barramento, indo do risco baixo ao risco alto. A classificação considera, ainda, a categoria de dano potencial que a barragem representa em função do potencial de perdas de vidas humanas e dos impactos econômicos, sociais e ambientais decorrentes de ruptura nas estruturas.

Das 14.966 represas, registradas até 30 de setembro de 2014, a imensa maioria, 13.366, ou 89\% do total, é de barragens com usos múltiplos de água, e 642 (4\%) são de barragens para geração de energia elétrica. Outras 295 (2\%) são barragens de contenção de resíduos industriais.

Ainda de acordo com dados Agencia Nacional de Águas (BRASIL, 2014), em seu Relatório de Segurança de Barragens, os três estados com maior número de barragens no país são: São Paulo (7.353 barragens, sendo 7.200 para usos múltiplos de água e 80 de rejeitos de mineração), Rio Grande do Sul (3.070 barragens, das quais 3.004 para usos múltiplos de água) e Minas Gerais (1.601 barragens, sendo 859 de usos múltiplos de água, 317 de contenção de resíduos de mineração, 289 de geração de energia elétrica e 136 de contenção de resíduos industriais).

São 116 barragens classificadas ao mesmo tempo como de Alto Risco e com Dano Potencial Associado. A ANA (BRASIL, 2014) destaca que a avaliação conjunta das barragens com Categoria de Risco Alto e Dano Potencial Associado permite concluir para quais barragens as "ações de acompanhamento, fiscalização e recuperação devem ser priorizadas, pois a categoria de risco alto significa maior número de ameaças à segurança da barragem e, por sua vez, o dano potencial alto indica que, em caso de um acidente, as consequências seriam graves".

Destaque-se que as barragens da Samarco, em Mariana, segundo a classificação da ANA, não eram consideradas de alto risco, ao contrário, eram consideradas de baixo, apesar de um 
laudo elaborado pelo Instituto Pristino, instituição particular sem fins lucrativos que realizou um estudo na região em 2013, a pedido do Ministério Público Estadual, MPE, haver concluído pelo alto risco de rompimento das barragens do Fundão e Santarém, ambas pertencentes à mineradora Samarco, alertando inclusive, para obras e modificações. Veja-se alguns apontamentos daquele laudo: Recomendações:

Recomenda-se que a condicionante de monitoramento geotécnico e estrutural dos diques e da barragem, seja realizada periodicamente, com intervalo inferior a um ano entre as amostragens. Este item foi apresentado no parecer único SUPRAM-ZM indexado ao PA 00015/1984/066/2008, contudo não consta nesta REVLO.

Recomenda-se a apresentação de um plano de contingência em caso de riscos ou acidentes. Além disso, a comprovação de efetividade do plano de contingência é condicionante, conforme deliberação Normativa COPAM n ${ }^{\circ} 62 / 2002$, dada à presença de população na comunidade de Bento Rodrigues, distrito do município de Mariana-MG. Esta condicionante não foi mencionada nesta REVLO.

Recomenda-se uma análise de ruptura (DAM - BREAK), que estava prevista para ser entregue à SUPRAM em julho de 2007, segundo PCA do projeto da Barragem de Rejeitos do Fundão. A validação do projeto final atrelada ao plano de monitoramento físico do empreendimento é de extrema importância para garantir a segurança e integridade do meio ambiente.

Evidenciando o problema: Sobreposição de áreas diretamente afetadas da Barragem do Fundão e da Pilha de Estéril União, da Mina de Fábrica Nova da Vale.

Somente na retificação do Projeto de Utilização Pretendida (PUP) há menção da sobreposição das duas áreas, o que resultou na alteração da área a ser suprimida pela Samarco. A empresa apresentou nova área de supressão, pois algumas áreas inseridas no primeiro documento pertenciam a Pilha de Estéril União, da Vale S/A, conforme Figura 1. Notam-se áreas de contato entre a pilha e a barragem. Esta situação é inadequada para o contexto 
de ambas estruturas, devido à possibilidade de desestabilização do maciço da pilha e da potencialização de processos erosivos. Embora todos os programas atuem na prevenção dos riscos, o contato entre elas não é recomendado pela sua própria natureza física. A pilha de estéril requer baixa umidade e boa drenagem; a barragem de rejeitos tem alta umidade, pois é reservatório de água.

As figuras a seguir ilustram, de maneira esquemática, como poderia ser a evolução de um processo de saturação na pilha adjacente à barragem de rejeitos do Fundão. No estágio na zona de contato entre a pilha de estéril e a barragem de rejeito, ocorreria a obstrução da drenagem da pilha e tentativa de equilíbrio do nível de água entre ambas as estruturas.

\section{As duas figuras que seguem fazem parte do relatório do Instituto Pristino}

\section{Nível da Água}

Barragem Fundão

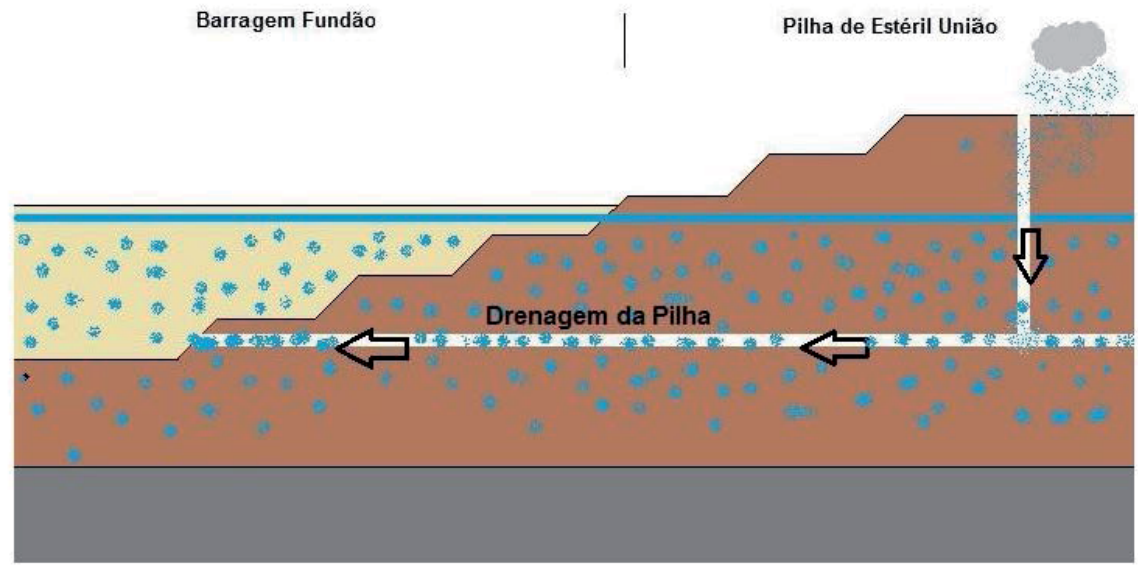

Cota 920 
Hilton NEVES FILHO; Daiane Machado REZENDE; Maria Luiza Santos COSTA;

Roy Reis FRIEDE

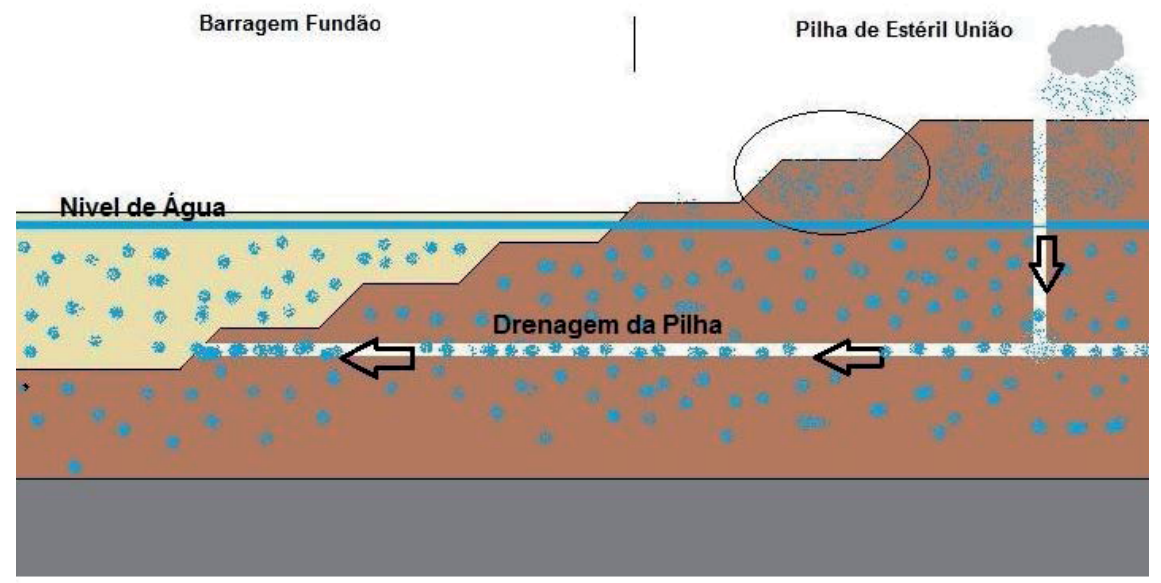

Figura 1 - Desenho esquemático de saturação do maciço da Pilha União - estágio I.

Com a evolução da saturação devido ao fluxo natural das águas superficiais resultantes da precipitação atmosférica (chuva), conforme apresentado na Figura a zona acima do nível de equilíbrio hidrostático ficaria saturada.

Na figura acima, o desenho esquemático de saturação do maciço da Pilha União - estágio II.

Tal situação ocasionaria a ressurgência de água nas faces dos taludes da pilha de estéril. A Figura 4, mostra de maneira simplificada a evolução em cinco subestágios da saturação e ressurgência de água. Além disso, ilustra a possibilidade de desestabilização da face do talude, resultando num colapso da estrutura.

Dependendo do raio da ruptura neste processo, podem ocorrer vários colapsos em diferentes níveis taludes e criar um fluxo de material com grande massa de estéril se deslocando para jusante em direção ao corpo da barragem do Fundão e adjacências.

Do relatório técnico do Instituto Pristino, encomendado pelo Ministério Público do Estado de Minas Gerais, destaca-se:

Com a evolução da saturação devido ao fluxo natural das águas superficiais resultantes da precipitação atmosférica (chuva), 
conforme apresentado na Figura 3 (estágio II), a zona acima do nível de equilíbrio hidrostático ficaria saturada. (fls. 4/7).

Tal situação ocasionaria a ressurgência de água nas faces dos taludes da pilha de estéril. A Figura 4, mostra de maneira simplificada a evolução em cinco subestágios da saturação e ressurgência de água. Além disso, ilustra a possibilidade de desestabilização da face do talude, resultando num colapso da estrutura. (fls. 5/7).

Dependendo do raio da ruptura neste processo, podem ocorrer vários colapsos em diferentes níveis taludes e criar um fluxo de material com grande massa de estéril se deslocando para jusante em direção ao corpo da barragem do Fundão e adjacências. (fls. 6/7).

Assim, a ruptura das barragens sob apreço, era uma tragédia anunciada desde 2013, e que, portanto, poderia e deveria ter sido evitada. Como não foram implementadas efetivas condutas capazes de sanear os problemas apontados no relatório do Instituto Prístino, o resultado é o que se tem hoje, qual seja, um retrato do descuido; eis que: 
Hilton NEVES FILHO; Daiane Machado REZENDE; Maria Luiza Santos COSTA;

Roy Reis FRIEDE

Bento Rodrigues era assim

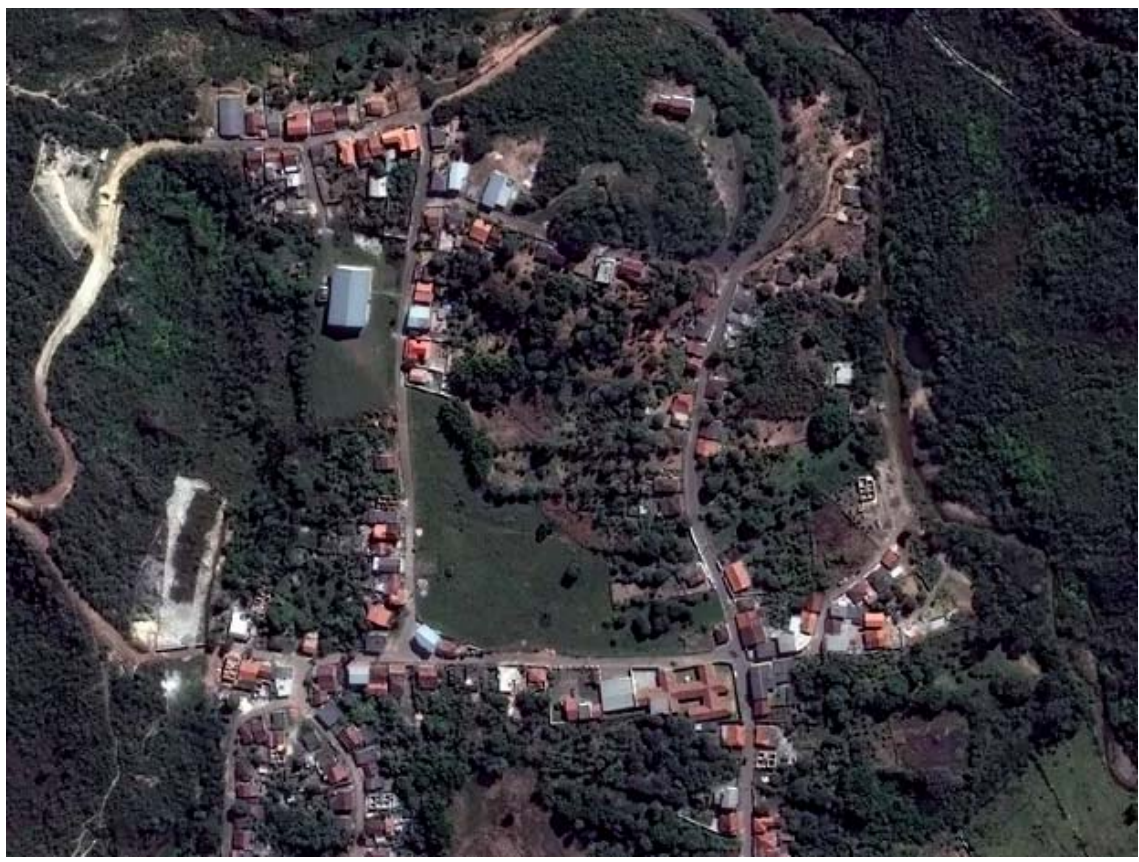

Figura 2 - Distrito de Bento Rodrigues antes de ser devastado pela lama das barragens (Foto: DigitalGlobe e Globalgeo Geotecnologias).

Fonte: <http://g1.globo.com/minas-gerais/noticia/2015/11/imagens-mostram-antes-e-depois-de-area-das-barragens-em-mariana.html> 


\section{E ficou assim}

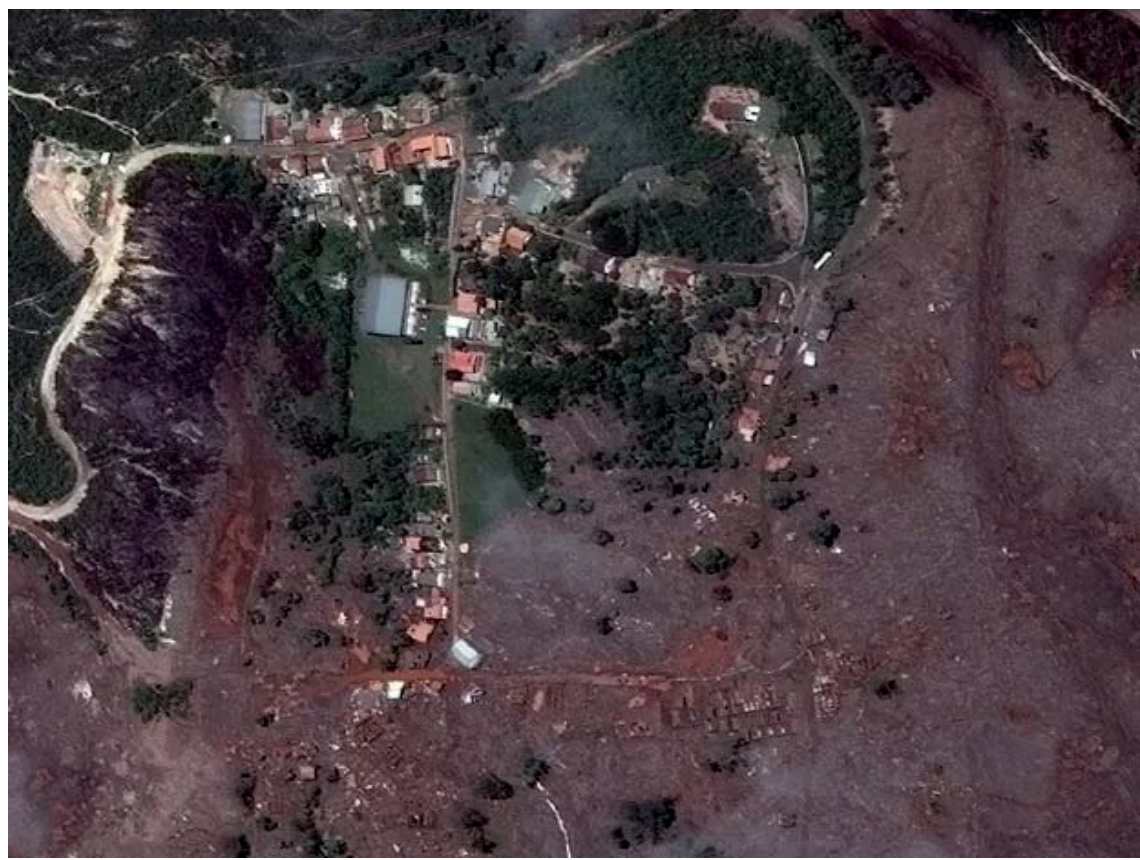

Figura 3 - Lama de barragens destruiu o distrito de Bento Rodrigues, em Mariana (Foto: DigitalGlobe e Globalgeo Geotecnologias). Fonte: <http://g1.globo.com/minas-gerais/noticia/2015/11/imagens-mostram-antes-e-depois-de-area-das-barragens-em-mariana.html >.

Conforme noticiado pela Revista, em 2013, quando a Samarco pediu novo licenciamento para a barragem do Fundão, o laudo técnico do Instituto Prístino, encomendado pelo Ministério Público de Minas Gerais, apontou risco de "colapso da estrutura" (CORRÊA, et al., 2015) , contudo e mesmo assim, o licenciamento foi concedido pela Secretaria de Meio Ambiente de Minas Gerais, tendo, em 2014, a Samarco aumentado a produção na unidade de Mariana em 33\% (CORREAA, et al., 2015).

Como demonstrado, face a potencial risco de colapso da barragem e de dano à coletividade e ao meio ambiente, cientes que 
estavam ou pelo menos deveriam estar, isto após a divulgação do relatório antes citado, os entes federais, o Estado de Minas através da FUNDAÇÃO ESTADUAL DE MEIO AMBIENTE, FEAM, órgão da Secretaria de Estado do Meio Ambiente e Desenvolvimento Sustentável, o MINISTÉRIO PUBLICO DO ESTADO DE MINAS GERAIS, a SECRETARIA MUNICIPAL DE MEIO AMBIENTE DO MUNICIPIO DE MARIANA-MG., deveriam ter agido determinando que a SAMARCO ultimasse protocolos necessários à segurança das estruturas tidas como comprometidas já para o volume de produção nos moldes de 2013 e não conceder novo licenciamento homologando a majoração da produção em um terço.

Os fatos comprovam que a tragédia é resultado de uma sucessão de erros, haja vista que muitos tinham a capacidade e competência para evitá-la, mas não agiram efetivamente com a urgência que o assunto reclamava, inclusa aí a própria mineradora, portanto o encargo pelo acontecido espraia-se por todos eles, que devendo, cada um dos envolvidos, de por si, responder na medida exata da sua respectiva culpabilidade.

\section{RESPONSABILIDADE CIVIL, NEXO E DANO, EM FACE DA TRAGÉDIA}

Para Sergio Cavalieri Filho (2016), por responsabilidade civil entende-se a ideia de obrigação, encargo, contraprestação, ou qualquer coisa que implique o dever de indenizar o prejuízo em virtude da violação de um outro dever jurídico.

0 dever de reparar decorre de uma obrigação prevista, seja pelo pacto entre as partes ou pelo ordenamento. Portanto a reparabilidade civil é a obrigação que uma pessoa adquire quando causa prejuízo a outra, não importando se o ato foi próprio da pessoa ou de pessoas ou coisa a ela ligada, tendo que reparar o dano causado, para que assim se restabeleça o equilíbrio propiciado pela lesão. 
Responsabilidade civil por dano ambiental decorrente do rompimento das barragens do Fundão, em Mariana, Minas Gerais

De uma relação de causalidade surgida entre o agente que praticou o ato lesivo e o prejuízo sofrido pela vítima, origina-se o dever de indenização, pois a Responsabilidade Civil não subsiste sem essa relação de causalidade entre o dano e a ação que o provocou. 0 nexo causal decorre do vínculo entre o prejuízo e a ação. É da ação do agente que o fato lesivo nasce.

Segundo Oliveira Filho (2009), para que um resultado possa ser atribuído a um determinado sujeito é preciso a existência de uma relação de causalidade entre a conduta deste e a consequência sobrevinda. E necessário que, entre a fase subjetiva da ação (conduta) e a fase objetiva desta (resultado) - medeie um vínculo. Mas esse vínculo não é apenas estático; pelo contrário, é dinâmico e produtivo. Não existe de um lado a ação e, de outro, o resultado, mas ação que provoca o resultado, a ação que deve causar o efeito.

O nexo representa uma relação necessária entre o evento danoso e a ação que o produziu, sendo que esta é considerada como sua causa. Entretanto, não será necessário que o dano decorra apenas imediatamente do fato que o produziu; deve-se verificar se o dano ocorreria, se o fato não tivesse acontecido. Este poderá não ser a causa imediata, mas, se for condição para a produção do dano, o agente será responsabilizado pelas consequências que advierem.

Para que ocorra o dever de ressarcimento, oriundo da Responsabilidade Civil, haverá a necessidade de ter ocorrido um dano, que o toma pressuposto dela. Dessa forma, para que ocorra o dever de reparação do dano, é necessário que ele tenha atingido o patrimônio da vítima ou sua moral. Esta última será vista em lugar apropriado. Assim, ao conceituarmos o dano, entenderemos melhor a Responsabilidade Civil objetiva, que rege o direito ambiental. Portanto, grosso modo, dano é todo prejuízo causado pelo agente, pois sem ele não haveria Responsabilidade Civil.

0 dano pode ser definido como a lesão (diminuição ou destruição) que, devido a certas circunstâncias, uma pessoa, contra 
sua vontade, pode sofrer em qualquer bem ou interesse jurídico, patrimonial ou moral. Juridicamente, dano é usualmente, tomado no sentido do efeito que produz: é o prejuízo causado, em virtude de ato de outrem, que vem causar diminuição patrimonial. Assim é que o dever de reparação do dano decorre de um prejuízo advindo como resultado de um dano provocado ao direito de outrem.

\section{A RESPONSABILIDADE CIVIL DO ESTADO POR DANO AMBIENTAL}

Como exsurge dos fatos trazidos à baila, o Estado através dos seus agentes, pelo menos desde 2013, tinha pleno conhecimento do potencial risco de quebra das barragens da SAMARCO que ruíram em 2015, impactando negativamente toda região e o meio ambiente do Rio Doce abaixo, tendo em vista que foi o próprio Ministério Publico Estadual que requereu a elaboração do relatório e da vistoria levada a efeito pelo Instituto Prístino, e se o MPE assim agiu, por certo, foi em virtude do conhecimento de que aquelas estruturas não se revestiam da segurança esperada.

Os contornos desidiosos são evidentes posto que em 2013 a conclusão do laudo já era taxativa ao apontar que a ruptura poderia acontecer a qualquer momento em caso de precipitação atmosférica, por esse viés não há como negar a responsabilidade do Estado por omissão, eis que deveria agir visando, a todo custo, impedir o desastre que se vislumbrava no horizonte.

É dever do Estado velar pela qualidade de vida e pela dignidade da pessoa humana. Como ensina Mauro Faria de Lima Filho (2014), dentre os múltiplos elementos que constituem o termo "qualidade de vida", destaca-se o acesso ao meio ambiente ecologicamente equilibrado, sendo impossível que uma pessoa tenha ingresso à saúde e bem-estar se o ambiente em que está inserida é carecedor de equilíbrio e preservação do estado das águas, solo, ar, flora, fauna e paisagem. 
Sem dúvida, é comum a degradação ambiental provocar um impacto de ordem psicológica, além da física, nos moradores da região afetada pela atividade danosa, não havendo nenhum óbice ao ressarcimento de tal dor imposta aos seres humanos vítimas dos agentes poluidores. Em suma, todo ato ou atividade que resulte em degradação dos recursos naturais, destruição de valores culturais da sociedade, na violação das condições básicas de saneamento, do trabalho e da saúde pública, e suas repercussões morais e econômicas, importa em dano ambiental, no sentido mais amplo do termo. (FARIA DE LIMA, 2014, p 70-1).

Por essa ordem claríssima de ideias, o Estado contribuiu adequadamente para o evento, à vista do acentuado grau de culpa por omissão, tendo em conta o MPE-MG estar ciente da fragilidade das barragens. Se os agentes estatais tivessem agido, como era de se esperar, o desafortunado evento, provavelmente, não aconteceria, e os danos não se teriam consolidado na vida das pessoas e sobre o meio ambiente.

Os danos existem e impõem aos responsáveis a obrigação inexorável de repará-los de forma ampla tendo em conta a inafastável culpa por procedimento imprudente e desidioso, do qual decorreu evidentes prejuízos ao meio ambiente e às pessoas.

A responsabilidade do poder público resta delimitado face a dano ecológico acarretado pela conduta negativa de seus agentes, isto porque à Administração Pública recaem obrigações legais sobre a preservação do meio ambiente, de modo que a mera omissão do órgão estatal que resultar em prejuízo ao direito alheio importa em responsabilização, e isso decorre da inteligência do artigo 225 da Constituição Federal que assim se refere:

Artigo 225. Todos têm direito ao meio ambiente ecologicamente equilibrado, bem de uso comum do povo e essencial à sadia qualidade de vida, impondo-se ao poder público eà coletividade o dever de defendê-lo e preservá-lo para as presentes e futuras gerações.

Verifique-se, ainda, que, por força constitucional do artigo $37 \S 6$, a responsabilidade do Estado é objetiva, não sendo 
necessário que o prejudicado prove a culpa da administração, basta haver uma relação de causalidade entre o ato prejudicial e a administração.

\section{A RESPONSABILIDADE CIVIL POR DANOS AMBIENTAIS}

Segundo José Ricardo Alvarez Vianna, (2011), filosoficamente a responsabilidade é decorrente do livre arbítrio, partindo-se da premissa de que somos livres para agir segundo nosso querer, pelo que devemos suportar os efeitos da nossa conduta, omissiva ou não, perante a sociedade.

Em tal sentido, para o Direito Ambiental, verifica-se por Responsabilidade Civil a resposta dada a todo aquele que degrada o meio ambiente. Se uma pessoa jurídica ou não, por seus agentes ou por si, age ou se omite resultando em danos ao meio ambiente, toda a sociedade arca com os efeitos prejudiciais uma vez que a degradação ambiental além dos imediatos e perceptíveis efeitos provoca incontáveis males às futuras gerações.

Além da questão da prejudicialidade difusa, o dano aqui tratado possui outras características gravosas, tais como, normalmente ocorrer de forma coletiva, é indivisível, é irreversível, não se restringe ao local da eclosão, possui efeitos cumulativos, afora outras consequências não listadas. Todas essas características exigem uma atenção especial no estudo dessa responsabilidade especifica, haja vista sua distinção da responsabilidade civil comum.

A atividade da SAMARCO implica, por sua índole, responsabilidade civil, nos termos do parágrafo único do artigo 927 do Código Civil, que estabelece a obrigação de reparar o dano, independentemente de culpa do agente, nos casos especificados em lei, ou quando da natureza da atividade desenvolvida pelo agente implicar eventual ofensa a direitos de terceiros.

Ocorre que, especificamente, sobre a responsabilidade civil ambiental, a Política Nacional do Meio Ambiente, Lei no 
6.938/81(17) prognostica que o agente poluidor está obrigado, involuntariamente da existência de culpa, a reparar os estragos ocasionados ao meio ambiente e às pessoas, decorrente da atividade, trata-se da teoria do risco integral, que não admite excludentes de responsabilidade de qualquer natureza, nem mesmo caso fortuito ou força maior.

\section{CONSIDERAÇÕES FINAIS}

Ao que tudo indica o rompimento das barragens da mineradora SAMARCO, em Mariana, Minas Gerais, em 2015, decorreu, sistemicamente, da falta de implementação das condutas esperadas de muitos agentes, sejam eles estatais ou não, e que tinham por obrigação precípua fiscalizar, além de velar pela estabilidade daquelas estruturas, posto que relatórios datados de 2013 apontavam para o risco do colapso e consequente sinistro, fato este que efetivamente veio a se consolidar modificando e destruindo o espaço natural.

Por certo compete a todo aquele que de alguma forma contribuiu para o evento danoso efetuar a devida reparação. Logo, a responsabilidade civil ambiental da SAMARCO e do Estado, pelo rompimento das barragens, é objetiva, ou seja, independe da comprovação de culpa, devendo estes suportarem o ônus a que as respectivas condutas, por seus agentes e representantes, deram causa. As reparações pelo sinistro não terão o condão de repor as perdas decorrentes do rompimento das barragens, posta a total impossibilidade de restauração do meio ambiente e das vidas ceifadas pelo desastre. Definitivamente, sem embargos de outras considerações, Bento Rodrigues foi varrido do mapa, e nunca mais na inteireza haverá possibilidade de recuperá-lo, a não ser pelo resgate das imagens nas memórias dos sobreviventes. 0 Direito Ambiental não dá conta dos transtornos movimentados com o rompimento das barragens, muitas questões políticas e sociais restarão pendentes sem solução. 
A SAMARCO é uma multinacional que explora minério de ferro, e, do processo exploratório e de beneficiamento, advêm rejeitos que não tem como aproveitar, estocando-os assim em reservatórios limitados e contidos por barragens eis que tais materiais não podem ser dispersos sem causar enormes danos ao meio ambiente e comunidades próximas, implicando, portanto no intervencionismo estatal e na edição de legislação específica para disciplinar a situação deveras problemática para a sociedade posto que inobstante francamente agressivos ao bioma, barragens e reservatórios de rejeitos são um mal necessário.

A legislação disponível sobre o assunto é moderna, contudo as construções de estilo são problemáticas, haja vista não passarem de áreas para acumulação de resíduos, em sua maioria, tóxicos, que não passam de lixo não reciclável estocados a céu aberto e que continuarão impactar negativamente o meio o ambiente mesmo após a mina ser exaurida ou a empresa pôr fim à exploração, isso sem falar da contaminação do lençol freático.

Resta evidenciado ser o arcabouço jurídico insuficiente para dar conta da questão decorrente do rompimento das barragens. 0 universo jurídico, por exemplo, não tem como promover o retorno do estado de antes na ruína dos mais de quinhentos quilômetros do leito do rio doce nem de suas águas, muito menos no perecimento da fauna e vida marinha irremediavelmente afetada pela lama tóxica que poluiu a costa do Estado do Espírito Santo.

Não há reparação financeira capaz de compensar o mal infringido à sociedade.

0 meio ambiente é um patrimônio de todos nós, pelo que, ao ser duramente atingido, como no caso da SAMARCO, além dos que viviam próximo, todos nós também fomos vitimados, portanto, doravante e para o sempre, a sociedade civil deve engajar-se promovendo ações fiscalizadoras para que tais ocorrências não se repitam. 
Responsabilidade civil por dano ambiental decorrente do rompimento das barragens do Fundão, em Mariana, Minas Gerais

\section{REFERÊNCIAS}

ALVAREZ VIANNA, José Ricardo. Responsabilidade civil por danos ao meio ambiente. Curitiba, 2011.

BRASIL. Agência Nacional de Águas (ANA). Relatório de Segurança de Barragens, 2014. Disponível em: <http://www2.ana.gov.br/Paginas/ imprensa/noticia.aspx?List=ccb75a86-bd5a-4853-8c76-cc46b7dc89a1 \&ID =12742>. Acesso em: 7 jul. 2016.

. Lei 12.334, de 20 de setembro de 2010. Estabelece a Política Nacional de Segurança de Barragens, cria o Sistema Nacional de Informações sobre Segurança de Barragens e dá outras providências. Disponível em: <http://www.planalto.gov.br/ccivil_03/_Ato20072010/2010/Lei/L12334.htm>. Acesso em: 7 jul. 2016.

. Constituição (1988). Constituição da República Federativa do Brasil. Brasília, DF: Senado Federal: Centro Gráfico, 1988.

. Lei 6.938, de 31 de agosto de 1981. Dispõe sobre a Política Nacional do Meio Ambiente, seus fins e mecanismos de formulação e aplicação, e dá outras providências. Disponível em: <http://www.planalto.gov.br/ ccivil_03/leis/L6938.htm>. Acesso em: 7 jul. 2016.

CAVALIERE FILHO, Sergio. Programa de Responsabilidade Civil. 12. ed. Rio de Janeiro: Atlas, 2016.

CORRÊA, Hudson; LIMA, Samantha; GOMIDE, Raphael. Mariana: os dramas e as culpas pela tragédia. Revista Época, 20 nov. 2015. Disponível em: <http://epoca.globo.com/tempo/noticia/2015/11/mariana-osdramas-e-culpas-pela-tragedia.html>. Acesso em: 7 jul. 2016.

FARIA DE LIMA, Mauro filho. Responsabilidade civil do estado pelo dano ambiental. Rio de Janeiro: Lumen Juris, 2014.

OLIVEIRA FILHO, Ari Alves. Responsabilidade civil em face dos danos ambientais. Rio de Janeiro: Ed. Forense, 2009.

RELATÓRIO Técnico do Instituto Pristino, 2013. Disponível em: https:// www.earthworksaction.org/files/pubs.../9.1-laudo-tecnico.pdf. Acesso em: 07 jul. 2016 
